\title{
PROJECT BASED LEARNING (PBL) DALAM KELAS BAHASA INGGRIS UNTUK MELATIH KREATIVITAS SISWA MEMAHAMI KONSEP CONTINUING PROFESSIONAL DEVELOPMENT (CPD)
}

\author{
Helsa Gita Almaida, Fidini Peparing Mauludi, Yolanda Sintia \\ gitacuzt@gmail.com \\ Mahasiswa Fakultas Keguruan dan Ilmu Pendidikan Universitas Ibn Khaldun
}

\begin{abstract}
ABSTRAK
PBL adalah pendekatan metodologis berdasarkan koperasi kontekstual belajar yang implementasinya mendorong perkembangan keterampilan kognitif, sosial, dan komunikatif peserta didik melalui keterampilan mereka keterlibatan dalam pelaksanaan tugas otentik. Penelitian ini bertujuan untuk membuat siswa kreatif dalam belajar bahasa Inggris. Data penelitian dikumpulkan dengan mengunakan instrumen kuesioner, interview, dan observasi. Hasil penelitian menunjukkan bahwa, (1) ada pengaruh yang signifikan model PBL terhadap kemampuan berpikir tingkat tinggi, (2) ada pengaruh kreativitas siswa terhadap kemampuan berpikir tingkat tinggi, dan (3) model PBL dan konsep CPD secara bersama-sama berpengaruh terhadap kemampuan berpikir tingkat tinggi.
\end{abstract}

Kata Kunci: project based learning, kreativitas siswa, konsep CPD.

\section{PENDAHULUAN}

\section{Menurut Johnson (2007) Project} based learniing (PBL) mampu menghubungkan muatan akademik dengan konteks dunia nyata, dalam hal ini proyek dapat membangkitkan antusiasme para siswa untuk turut berpartisipasi dalam kegiatan pembelajaran. PBL adalah pendekatan metodologis berdasarkan koperasi kontekstual belajar yang implementasinya mendorong perkembangan keterampilan kognitif, sosial, dan komunikatif peserta didik melalui keterampilan mereka keterlibatan dalam pelaksanaan tugas otentik (Willis dan Willis 2007). Namun, minat belajar Bahasa Inggris yang dimiliki siswa saat ini sangatlah rendah. Anderson (2015) mengatakan penyebab kurang minat belajar siswa yaitu menggambarkan masalah sebagai seorang guru dan menganggap keheningan pelajar sebagai tembok. Namun, ia juga bersimpati dengan frustrasi siswa dengan guru yang, alih-alih memahami tanggapan mereka, tafsirkan sebagai kurangnya inisiatif atau penolakan untuk berpartisipasi. Namun, minat belajar siswa pada saat ini sangatlah rendah. Berdasarkan data Global Human Capital Report, diterbitkan World Economic Forum tahun 2017, peringkat Indonesia dalam urusan pendidikan menempati peringkat 65 dari 130 negara. Posisi itu masih jauh tertinggal dari negara-negara anggota ASEAN (Association of Southeast Asian Nations), misalnya Singapura (12), Malaysia (33), Thailand (40), dan Filipina (50). Menurut (Edy Zaqeus: 2008) Rasa malas diartikan sebagai keengganan 
seseorang untuk melakukan sesuatu yang seharusnya atau sebaiknya dia lakukan. Hal ini disebabkan karena kurangnya minat belajar siswa. Untuk meningkatkan minat belajar siswa, konsep Continuing Profesional Development (CPD) yang sesuai dalam membantu untuk meningkatkan minat belajar. Menurut (Mann 2005 : 105) ada peningkatan minat dalam beberapa tahun terakhir pada guru dan siswa untuk melanjutkan pengembangan profesional (CPD) dengan berbagai cara.

Memastikan pengembangan profesional berkelanjutan (CPD) berkualitas tinggi peluang tersedia bagi guru bahasa Inggris di sekitarnya dunia adalah perhatian utama bidang ELT, dan penelitian tindakan (AR) adalah salah satu model yang semakin ditawarkan sebagai bagian dari CPD. Sebagai (Burns 2013) menjelaskan, AR melibatkan guru yang mengambil 'tindakan', seringkali dalam bentuk sebuah intervensi untuk menyelidiki secara sistematis, melalui 'penelitian', ruang kelas masalah yang mereka rasa perlu ditelusuri untuk lebih memahami atau meningkatkan sebuah aspek pengajaran atau pembelajaran. Siklus AR perencanaan, tindakan, pengamatan, dan refleksi diterapkan untuk mengumpulkan bukti untuk mendukung pemahaman atau peningkatan. Contoh terbaru dari AR yang digunakan sebagai bagian dari CPD termasuk proyek British Council di Chili (Smith, Connelly, dan Rebolledo 2014). Untuk memahami konsep CPD siswa dilatih untuk kreativitas. Kreativitas yaitu suatu kemampuan yang dimiliki untuk menciptakan suatu hal yang baru. Kreativitas salah satu kebutuhan pokok manusia yaitu kebutuhan akan perwujudan diri (aktualisasi diri) dan merupakan kebutuhan yang paling tinggi bagi manusia (Maslow, dalam Munandar, 2009). Kreatif dapat diidentifikasi dan dipupuk melalui pendidikan yang tepat (munandar, 2009).

Teknik untuk mengoptimalkan kreativitas belajar siswa dalam bahasa iggris materi speaking yang diwujudkan melalui metode seperti dokumentasi observasi dan penarikan data, reflektif praktik juga merupakan bagian dalam bentuk penelitian praktisi seperti praktik eksplorasi dan penelitian tindakan eksplorasi.

Tujuan dari penelitian ini ialah untuk mengoptimalkan minat belajar siswa dalam bahasa Inggris dengan memahami konsep CPD terhadap kreativitas siswa. 


\section{METODE PENELITIAN}

Metode ini kami lakukan dengan mengumpulkan data berdasarkan kuesioner, interview, dan observasi yang merupakan salah satu jenis pengumpulan data yang terdapat dalam metode penelitian kualitatif. Menurut (David Williams 1995) bahwa penelitian kualitatif adalah pengumpulan data pada suatu latar alamiah, dengan menggunakan metode alamiah, dan dilakukan oleh orang atau peneliti yang tertarik secara alamiah. Penelitian dilakukan malalui 3 tahap dengan kurun waktu 1 minggu yaitu pada tanggal 21 Desember 2018 dilingkungan FKIP Universitas Ibn Khaldun Bogor.

Tahap pertama, kami mengumpulkan 9 reponden yang berasal dari kelas 3A Speaking. Kesembilan responden tersebut tidak asing dengan penggunakan kuisioner, kami mencoba memberikan beberapa pertanyaan untuk memperoleh informasi yang relevan. (Sudarwin 2002) menyatakan bahwa peneliti sebagai instrumen dalam penelitian kualitatif mengandung arti bahwa peneliti

\section{HASIL PENELITIAN}

Kuesioner, Interview dan observasi sebagai cara dalam pengumpulan data yang kami lakukan, menjadi tahap akhir dalam penelitian ini.

Setelah itu saya mengajukan 5 pertanyaan dalam bentuk kuesioner yang berkaitan dengan projek yang mereka pilih serta pendapat mereka tentang projek speaking untuk memahami konsep CPD.

1. Apakah anda menyukai tugas speaking yang berbentuk projek? melakukan kerja lapangan secara langsung dan bersama beraktivitas dengan orangorang yang diteliti untuk mengumpulkan data.

Tahap kedua, yaitu tahap interview. Sebelum melakukan interview, kami meminta responden terlebih dahulu tentang project speaking, dalam interview ini kami memberikan beberapa pertanyaan berkaitan dengan project speaking dengan jawaban berupa opini responden. Jenis interview yang kami gunakan ialah interview persuasif bertujuan untuk mengetahui cara seseorang responden berpikir, merasa, dalam suatu tindakannya. Teknik pengumpulan data merupakan cara pengumpulan data yang dibutuhkan untuk menjawab rumusan masalah penelitian (Juliansyah Noor 2011:138).

Tahap ketiga, ditahap ketiga ini kami melakukan observasi karena dengan teknik ini kami dapat melakukan pengambilan data secara relevan. Kami bisa mengamati kondisi interaksi siswa dalam pembelajaran.

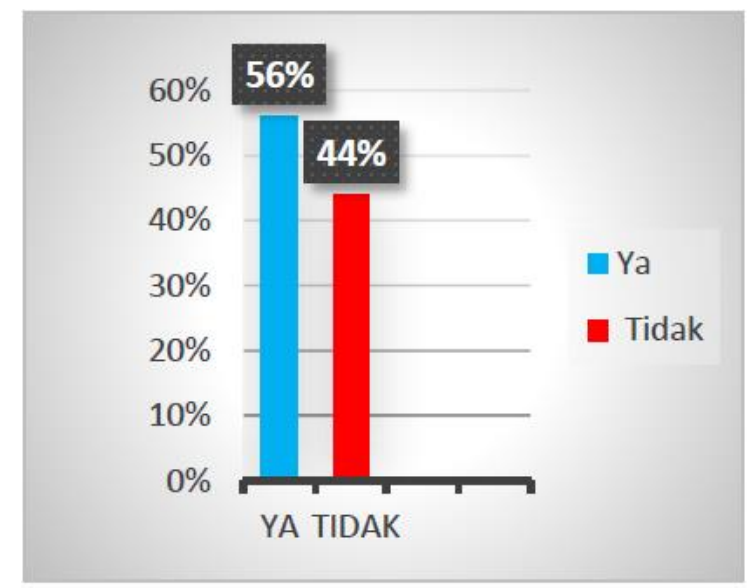


2. Apakah anda berusaha mengerjakan tugas sebaik mungkin?

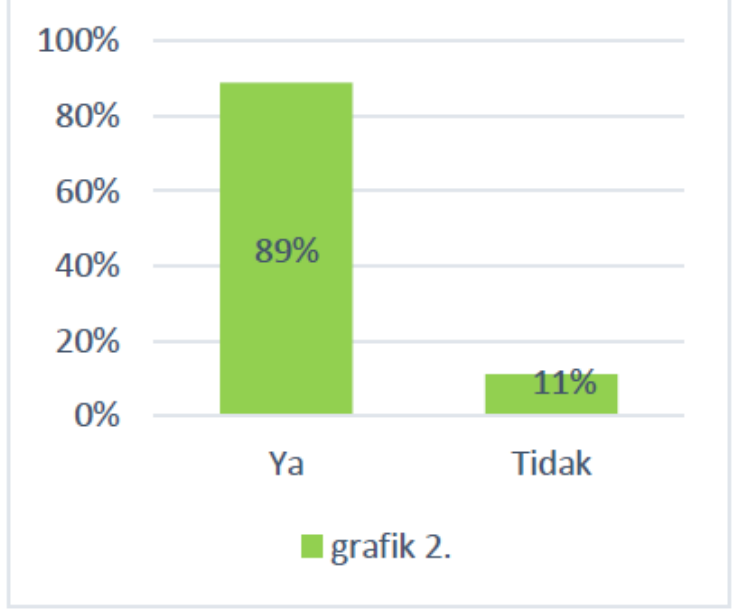

3. Apakah yang anda kerjakan ketika mengalami kesulitan dalam mengerjakan projek tersebut?

\begin{tabular}{|l|c|}
\hline Responden & $\begin{array}{l}\text { Hasil persentase } \\
\text { pembahaman siswa }\end{array}$ \\
\hline $\begin{array}{l}\text { Bertanya kepada } \\
\text { teman }\end{array}$ & $44 \%$ \\
\hline $\begin{array}{l}\text { Mencari tahu } \\
\text { sendiri dengan } \\
\text { bantuan google }\end{array}$ & $34 \%$ \\
\hline $\begin{array}{l}\text { Mengerjakan } \\
\text { sebisanya }\end{array}$ & $22 \%$ \\
\hline
\end{tabular}

4. Ketika projek sedang dikerjakan apakah anda belajar atau menemukan sesuatu yang baru?

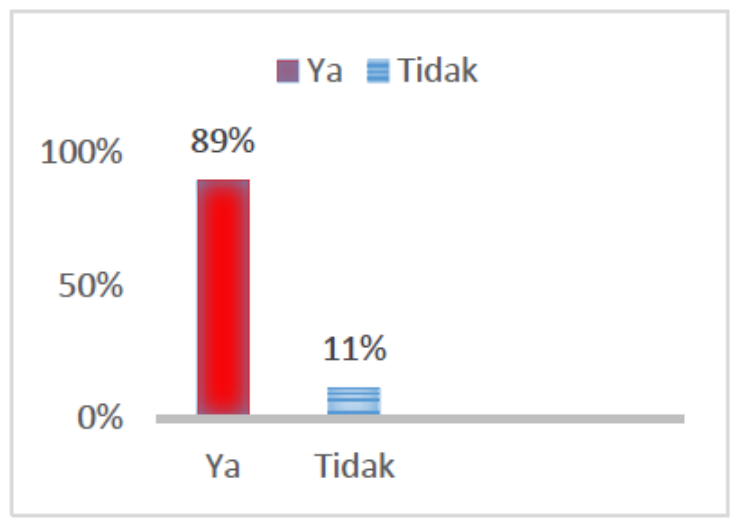

5. Adakah strategi yang anda pelajari atau dapatkan dalam mengerjakan projek yang akan anda gunakan lagi? Jelaskan dengan singkat?

\begin{tabular}{|c|l|}
\hline $\begin{array}{c}\text { Responden } \\
\text { Ke }\end{array}$ & \multicolumn{1}{|c|}{ Jawaban } \\
\hline 1 & $\begin{array}{l}\text { Saya memakai google } \\
\text { translate dan aplikasi lainnya }\end{array}$ \\
\hline 2 & $\begin{array}{l}\text { Praktik speaking dengan } \\
\text { berbicara dengan teman dan } \\
\text { foreigner }\end{array}$ \\
\hline 3 & $\begin{array}{l}\text { Mengerjakan dengan } \\
\text { organisasi }\end{array}$ \\
\hline 4 & $\begin{array}{l}\text { Ya ada, saya belajar dengan } \\
\text { teman }\end{array}$ \\
\hline 5 & $\begin{array}{l}\text { Saya mencari pengalaman } \\
\text { diluar }\end{array}$ \\
\hline 6 & $\begin{array}{l}\text { Ada, saya belajar diluar } \\
\text { dengan diskusi bersama }\end{array}$ \\
\hline 7 & Tidak ada \\
\hline 8 & Tidak ada \\
\hline 9 & Tidak ada \\
\hline & \\
\hline
\end{tabular}


Tahap ke-2 pengambilan data kami melakukan interview dalam mengumpulkan data penelitian ini, saya mengajukan 3 pertanyaan berkaitan dengan projek speaking untuk memahami konsep CPD.

\begin{tabular}{|c|c|c|}
\hline Responden ke- & Pertanyaan & Jawaban \\
\hline 1 & $\begin{array}{l}\text { Apakah anda merasa aktif } \\
\text { dan mudah menyampaikan } \\
\text { pendapat dalam belajar } \\
\text { projek speaking? Jelaskan } \\
\text { dengan singkat! }\end{array}$ & $\begin{array}{l}\text { Iya, karena dalam berlajar } \\
\text { projek speaking saya } \\
\text { merasakan perbedaan dimana } \\
\text { saya diajarkan untuk untuk } \\
\text { percaya diri dalam berbicara }\end{array}$ \\
\hline 2 & $\begin{array}{l}\text { Apakah anda sering praktik } \\
\text { speaking di kelas dan diluar } \\
\text { kelas? Jelaskan dengan } \\
\text { singkat! }\end{array}$ & $\begin{array}{l}\text { Iya, karena dalam } \\
\text { mengupgrade projek speaking } \\
\text { membutuhkan praktik di kelas } \\
\text { dan diluar kelas supaya } \\
\text { dapatkan hasil yang maksimal }\end{array}$ \\
\hline 3 & $\begin{array}{l}\text { Apa yang anda lakukan } \\
\text { dalam mengerjakan projek } \\
\text { speaking agar mendapatkan } \\
\text { hasil yang maksimal? }\end{array}$ & $\begin{array}{l}\text { Terus belajar dan mencari } \\
\text { sesuatu hal yang tidak } \\
\text { diketahui dalam mengerjakan } \\
\text { projek speaking dengan } \\
\text { mudah. }\end{array}$ \\
\hline
\end{tabular}

Setelah memberikan kuesioner dan interview, di tahap ke- 3 yaitu tahap terakhir dalam pengumpulan data penelitian ini kami melakukan observasi, karena dengan teknik ini kami dapat melakukan pengambilan data secara relevan. Kami bisa mengamati kondisi interaksi siswa dalam pembelajaran.

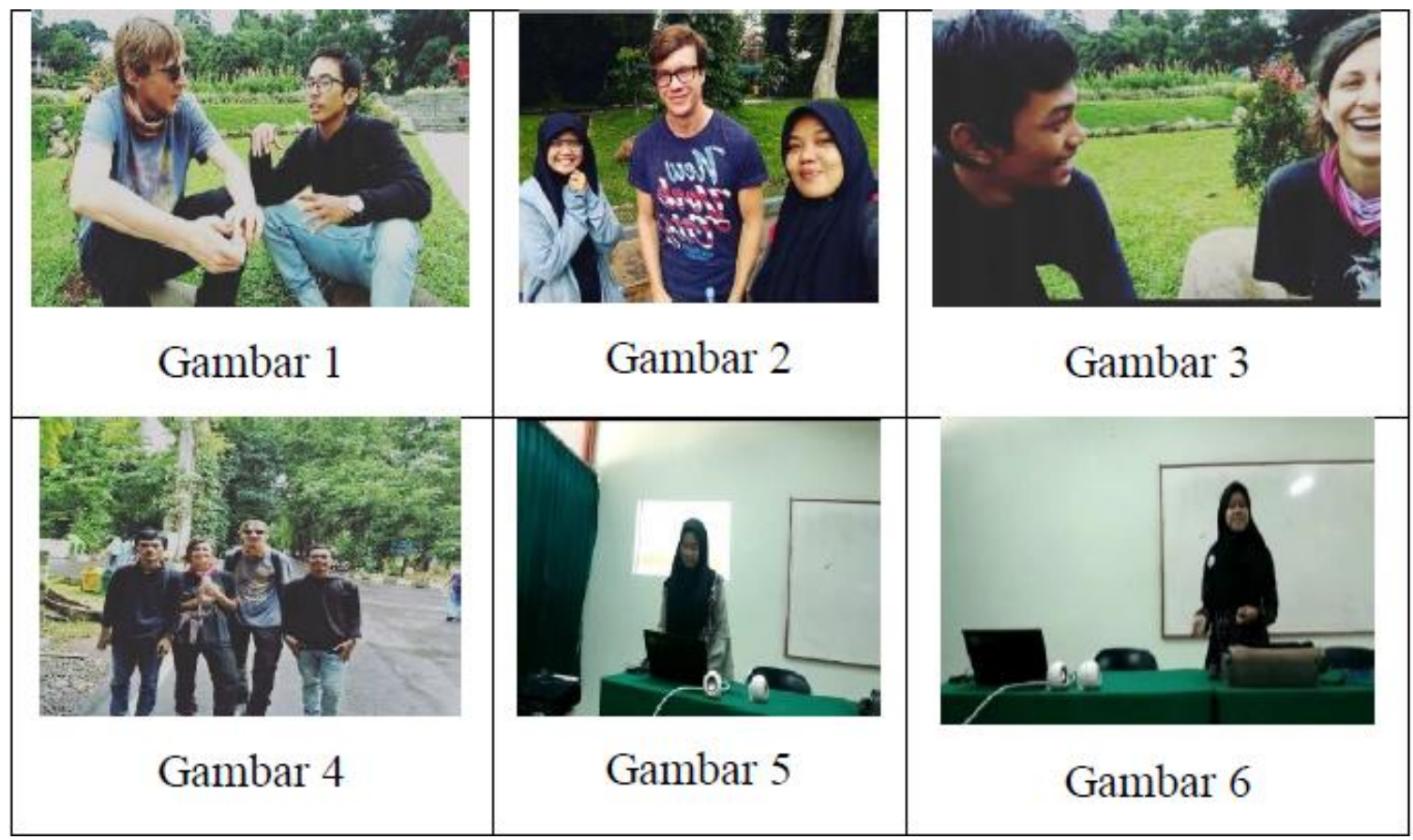




\section{PEMBAHASAN}

Dalam pembahasan dari hasil kuesioner tersebut terdapat beberapa kesimpulan dari setiap point yang dinyatakan yaitu sebagai berikut, hasil dari kuesioner pernyataan ke- 1 , menunjukan bahwa siswa menyukai metode projek dalam mengerjakan materi speaking. Hanya ada 4 responden yang tidak menyukai metode projek dalam speaking. Hasil dari kuesioner yang ke- 2 diperoleh adanya usaha siswa untuk mengerjakan tugas projek speaking dengan baik, meskipun hanya 1 responden yang merasakan kesulitan dalam mengerjakan projek speaking karena lebih tertarik dengan projek yang lainya. Hal tersebut di jelaskan dengan hasil dari kuisioner pada pertanyaan 3 dengan menyatakan responden mengungkapkan bahwa mengerjakan projek speaking dengan semampunya. Beberapa responden memilih untuk menyelesaikan projek speaking dengan menggunakan google dan bertanya kepada teman setidaknya siswa mengetahui $78 \%$ dari projek speaking. Hasil dari kuesioner ke- 4, menunjukan

\section{KESIMPULAN}

Pemahamaan siswa terhadap konsep CPD sangat berpengaruh karena tanpa adanya pemahaman, dan kreativitas tidak akan mampu mengoptimalkan belajar bahasa Inggris. Sehingga, kegiatan belajar tidak optimal dan membosankan. Oleh karena itu memahami kosep CPD yang mampu meningkatkan minat siswa adalah bahwa siswa memperoleh hal baru ketika mengerjakan projek speaking. Hasil interview ke-5 juga memiliki keterkaitan yang sama yaitu siswa memiliki respon yang positif terhadap memahami konsep CPD dan dapat membantu mereka untuk berkreativitas dalam mengoptimalkan speaking skill.

Hasil dari data interview diatas menjelaskan bahwa siswa merasa aktif dalam mengerjakan projek speaking dan siswa selalu mengupgrade ilmu yang dimiliki dengan cara praktik speaking di kelas maupun diluar kelas dan siswa pun selalu mencari hal-hal baru untuk mendapatkan pengetahuan yang baru dalam projek speaking agar mendapatkan hasil yang maksimal.

Dari hasil observasi dapat dilihat bahwa siswa sering melakukan praktik speaking agar bisa mengoptimalkan projek speaking dimana siswa yang belum percaya diri dalam menyampaikan pendapat sekarang mereka mulai berlatih untuk mencari hal-hal baru dalam projek speaking.

hal yang terpenting. Memahami konsep CPD hadir sebagai jawaban yang mampu meningkatkan minat belajar yang efektif, kreativitas siswa dalam belajar dan mengupgrade ilmu pengetahuan. Sehingga memahami konsep CPD memiliki pengaruh yang positif terhadap kemampuan dalam belajar bahasa Inggris. 


\section{DAFTAR PUSTAKA}

Anderson, L.W. \& Krathwohl, D.R. (Eds). 2015. Kerangka landasan untuk pembelajaran, pengajaran, dan asesmen: revisi taksonomi pendidikan Bloom.(Terjemahan Agung Prihantoro). Yogyakarta: Pustaka Pelajar. Anjarini.

Burns, R. B. (2013). The self Concept. London : Pan Books

Bloom.(Terjemahan Agung Prihantoro). Yogyakarta: Pustaka Pelajar. Anjarini.

Johnson, E.B. 2008. Contextual Teaching \& Learning: Menjadikan Kegiatan Belajar-Mengajar Mengasyikkan dan Bermakna. Bandung: MLC.

Mann, S. 2005. 'The language teacher's development'. Language Teaching 38/3: 103-18.
Munandar. (2009). Pengembangan Kreativitas Anak Berbakat. Jakarta: Rineka CIpta. Mann, S. and S. Walsh. 2013. 'RP or "RIP": a critical perspective on reflective practice'. Applied Linguistics Review 4/2: 291-315.

Noor, A. M. 2009. Pedagogical Issues in integrating Thinking Skills in The Classroom. International Journal for Education Studies, 2(1): 55-68. DOI:10.26822/iejee.2018336189

Smith, R., T. Connolly, and P. Rebolledo. 2014. 'Teacher research as continuing professional development: a project with Chilean secondary school teachers' in D. Hayes (ed.). Innovations in the Continuing Professional Development of English Language Teachers. London: British Council. 